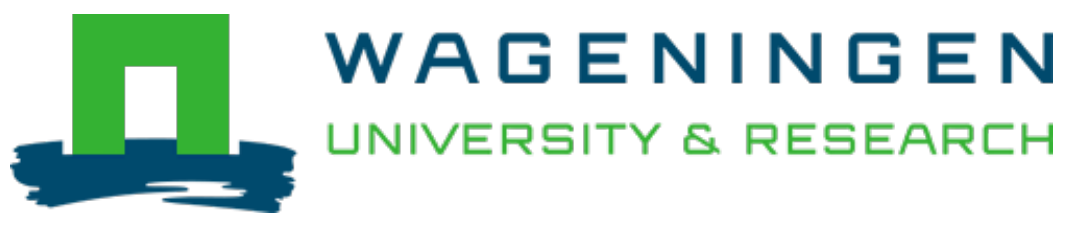

\title{
Welfare issues in poultry housing and management: broilers
}

Understanding the behaviour and improving the welfare of chickens

Jong, I.C.

https://doi.org/10.19103/AS.2020.0078.10

This article is made publicly available in the institutional repository of Wageningen University and Research, under the terms of article $25 \mathrm{fa}$ of the Dutch Copyright Act, also known as the Amendment Taverne. This has been done with explicit consent by the author.

Article $25 \mathrm{fa}$ states that the author of a short scientific work funded either wholly or partially by Dutch public funds is entitled to make that work publicly available for no consideration following a reasonable period of time after the work was first published, provided that clear reference is made to the source of the first publication of the work.

This publication is distributed under The Association of Universities in the Netherlands (VSNU) 'Article $25 \mathrm{fa}$ implementation' project. In this project research outputs of researchers employed by Dutch Universities that comply with the legal requirements of Article $25 \mathrm{fa}$ of the Dutch Copyright Act are distributed online and free of cost or other barriers in institutional repositories. Research outputs are distributed six months after their first online publication in the original published version and with proper attribution to the source of the original publication.

You are permitted to download and use the publication for personal purposes. All rights remain with the author(s) and / or copyright owner(s) of this work. Any use of the publication or parts of it other than authorised under article $25 \mathrm{fa}$ of the Dutch Copyright act is prohibited. Wageningen University \& Research and the author(s) of this publication shall not be held responsible or liable for any damages resulting from your (re)use of this publication.

For questions regarding the public availability of this article please contact openscience.library@wur.nl 
Understanding the behaviour and improving the welfare of chickens

Edited by Professor Christine Nicol

Royal Veterinary College - University of London, UK

\section{ECHIAPTER FROIVI THIS BOOK}

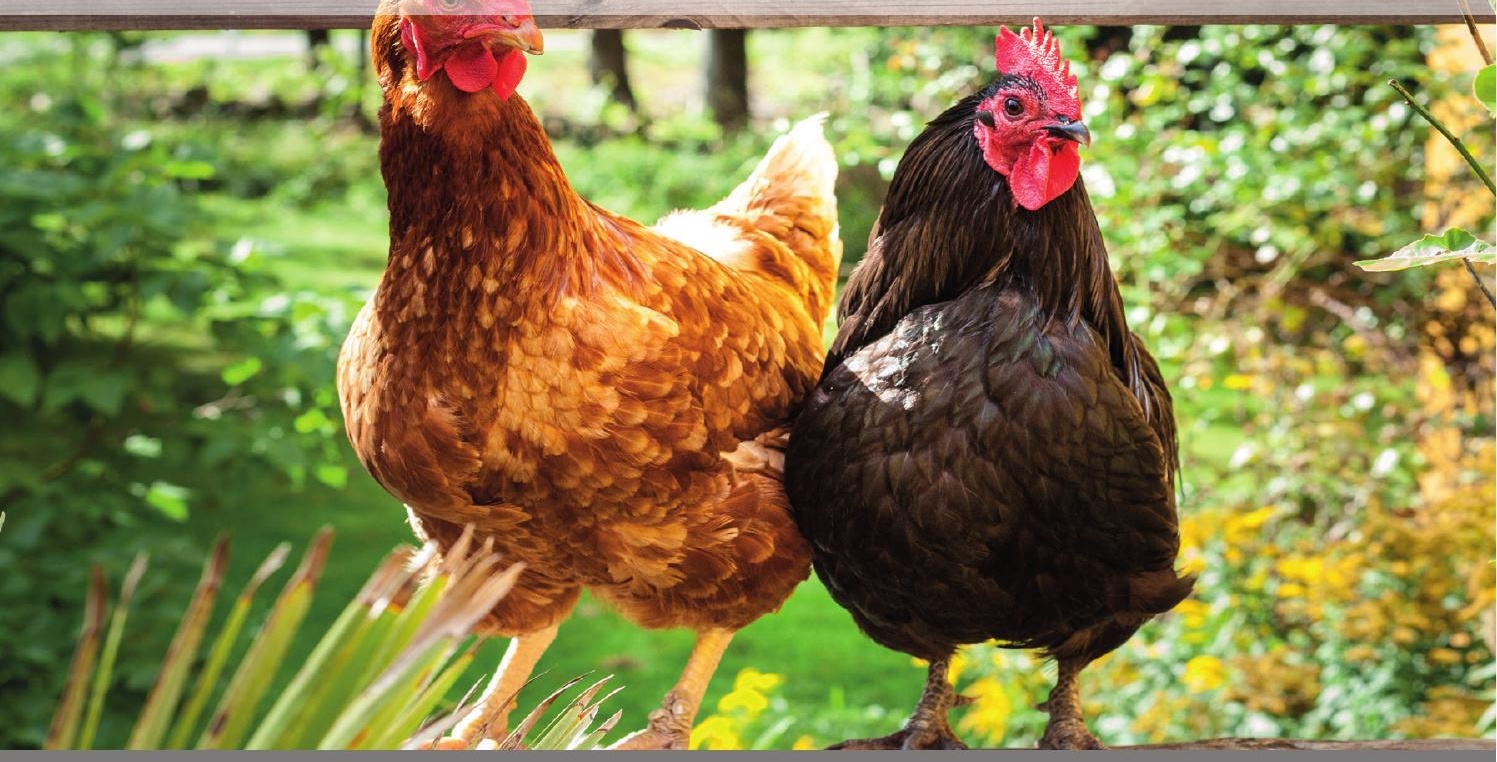




\title{
Welfare issues in poultry housing and management: broilers
}

\author{
Ingrid C. de Jong, Wageningen Livestock Research, Wageningen University and Research, \\ The Netherlands \\ 1 Introduction \\ 2 Broiler behaviour and space use \\ 3 Welfare issues in broiler chicken production: leg health, heat stress and \\ behavioural restrictions \\ 4 The relationship between growth rate and broiler welfare \\ 5 Effects of environment and management on welfare \\ 6 Conclusions and future trends \\ 7 Where to look for further information \\ 8 References
}

\section{Introduction}

Worldwide, more than 60 billion broiler chickens are reared and slaughtered for meat production on a yearly basis. Poultry meat production even exceeded pork production in 2018, with a worldwide production of more than 123 million metric tons per year (Statistica, 2019). The majority of broiler chickens worldwide are of a conventional, fast-growing breed and are housed in indoor systems with a fully littered floor with either mechanical or natural ventilation (Fig. 1). Feed and water are provided automatically and feeders and drinkers are distributed over the house. The standard broiler house has no windows, but windows can be present in the side walls or the roof. Depending on the local climate open-sided houses can also be used, such as in Brazil (Federici et al., 2016) and southern Europe (de Jong et al., 2012a). In Europe the litter is usually completely removed in between production cycles and houses are cleaned and disinfected, but in other countries, such as the United States, litter can be re-used (Cengiz et al., 2011). In the major producing countries the number of broiler chickens per house is usually between several thousands, around 30 000-50 000 chickens per house. Stocking densities also vary between countries, for example, in Europe in indoor systems a maximum density of $38-42 \mathrm{~kg} / \mathrm{m}^{2}$ is a normal 

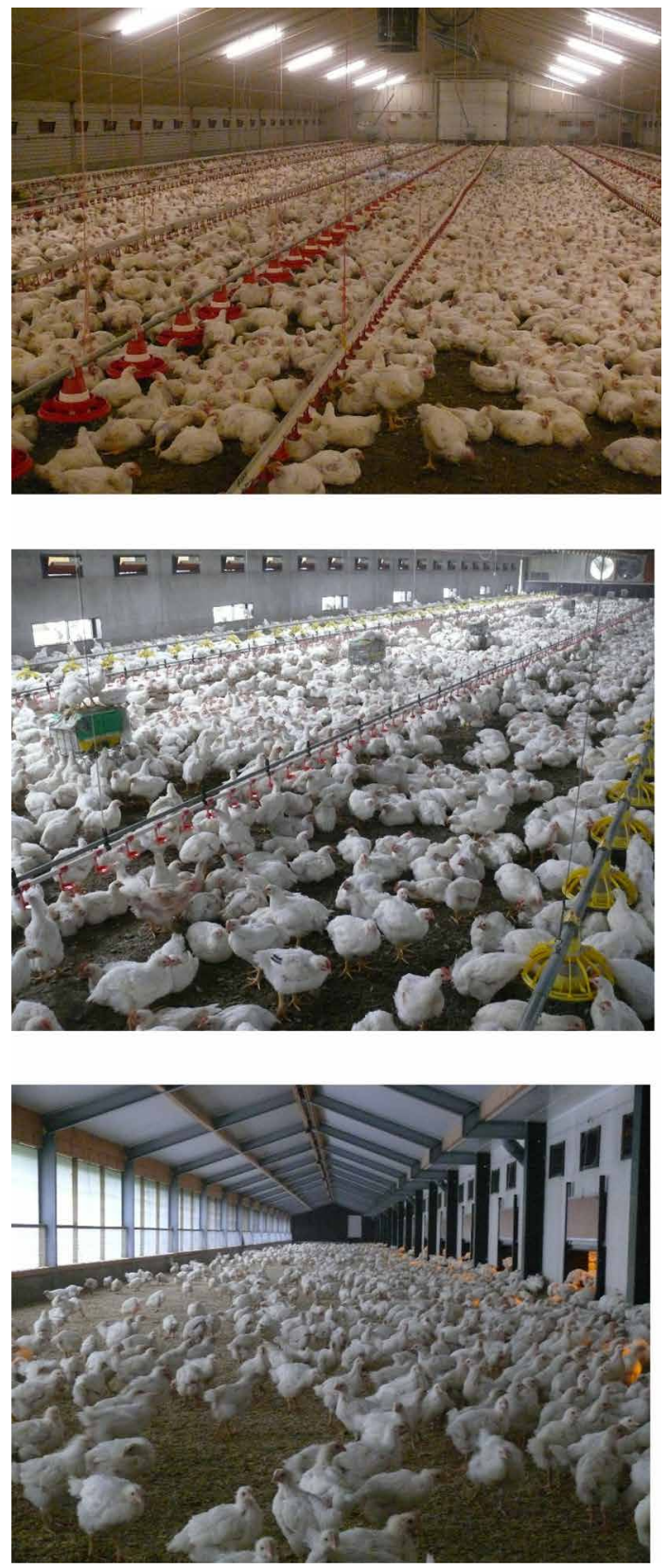

Figure 1 Examples of broiler production systems: indoor system without windows and conventional fast-growing breed (upper picture), and an example of a higher welfare system with a slow-growing breed enrichment (here: Lucerne bales in racks), a reduced stocking density and covered outdoor range (middle and lower picture) (Pictures: Ingrid de Jong, Wageningen Livestock Research). 
practice, according to the specifications in the EU Broiler Directive (European Commission, 2007), although in some countries lower maximum densities are allowed such as $30 \mathrm{~kg} / \mathrm{m}^{2}$ in Austria and $36 \mathrm{~kg} / \mathrm{m}^{2}$ in Sweden (European Commission, 2016). In the United States stocking densities in conventional systems are around $37 \mathrm{~kg} / \mathrm{m}^{2}$ and in Brazil between $34 \mathrm{~kg} / \mathrm{m}^{2}$ and $38 \mathrm{~kg} / \mathrm{m}^{2}$ depending on the type of house (open-sided or tunnel-ventilated) (Vissers et al., 2019). The light intensity in Europe should be at least 20 lux at animal height, as defined in the Broiler Directive (European Commission, 2007), but it can be as low as 5 lux in conventional systems in countries such as the United States and Brazil in windowless houses (Vissers et al., 2019).

Since 2008, in Russia, the Middle East and Asia cage systems are increasingly being used for broiler chickens (e.g. Bracke et al., 2019b). These 'new' cage systems are colony cages with plastic-covered nylon floors and automated systems for depopulation of the chickens using conveyor belts. However, the fact that broiler chickens are still housed in battery cages designed for laying hens, for example, in African countries cannot be ignored (Shields and Greger, 2003).

In contrast, especially in countries in Northwestern Europe, there is an increasing demand for so-called 'higher-welfare' systems, resulting in an increased use of indoor systems with lower stocking densities, environmental enrichment and sometimes a covered veranda (Saatkamp et al., 2019; de Jonge and van Trijp, 2014; RSPCA, 2006; Vissers et al., 2019; Bergmann et al., 2016) (Fig. 1), free-range systems, or broiler chickens kept on pasture (usually organic broiler production systems). Free-range houses are usually similar to indoor production houses, but have pop holes for access to the covered veranda ('free-range indoor') or outdoor range. Pasture systems usually have smaller flock sizes and may include mobile houses (Sossidou et al., 2015). Whereas the majority of broiler chickens in conventional indoor systems are usually of a standard, fast-growing breed, slower-growing broiler strains are usually housed in higher-welfare or pasture systems (Saatkamp et al., 2019; Bergmann et al., 2016; Sossidou et al., 2015). In, for example, Sweden, these have only been introduced recently whereas previously fast-growing broilers were used in organic systems (Wilhelmsson et al., 2019). Slow-growing broiler chickens are usually broiler chickens produced by slow-growing female parent stock that are crossed with a regular or slow-growing male, resulting in a daily growth rate of about $50 \mathrm{~g}$ or lower at slaughter weight (2.3-2.5 kg) (Ellen et al., 2012; Saatkamp et al., 2019), whereas fast-growing broiler strains may have an average daily growth rate of more than $65 \mathrm{~g}$ at similar slaughter weights (Aviagen, 2019). As a consequence, similar slaughter weights are reached at different ages, that is, around 38 days of age for fast-growing strains, and vary between 46 and 81 days of age for slow-growing strains depending on the daily growth rate. 


\subsection{Genetic selection for growth potential and broiler welfare}

There are only three large breeding companies that produce the majority of broiler chickens worldwide. Broiler chickens have been selected intensively for growth, feed efficiency and meat production over the past decades. This means that they have the potential to grow to slaughter weight in a relatively short time with a very low feed conversion rate, provided conditions to do so are (near) optimal. For example, Zuidhof et al. (2014) showed that from 1957 to 2005 , broiler growth rates have increased by over $400 \%$, with a concurrent $50 \%$ reduction in feed conversion ratio. This means that a body weight of $2.5 \mathrm{~kg}$ can be reached in just 38 days (e.g. Aviagen, 2019). Although some of these changes have been attributed to improved housing and management, it was estimated that $85-90 \%$ of this achievement could be attributed to genetic selection. The intensive genetic selection, however, has also been shown to lead to concomitant adverse effects on welfare and health, such as leg disorders, metabolic disorders and impaired immune function (Bessei, 2006; EFSA, 2010). This does not mean that breeding companies do not include welfare and health improvement in their selection process. Breeding companies select for optimal leg strength, heart and lung fitness, and against contact dermatitis, and they are culling birds with a family record or signs of genetic abnormalities. For some traits this has already been done for 25 years (Hiemstra and Ten Napel, 2011). For some metabolic disorders (e.g. ascites) and some leg disorders, genetic selection has also been successful in decreasing the prevalence (Hiemstra and Ten Napel, 2011). However, welfare problems linked to genetic selection for efficient growth in broiler chickens are still present, such as leg disorders and health problems in broiler chickens, and the associated feed restriction in the parent stock which is discussed elsewhere in this chapter (de Jong et al., 2012a; Dawkins and Layton, 2012). It has been estimated that the relative weighting of all welfare traits in the combined breeding goal varied from $18 \%$ to $33 \%$ across breeding companies in 2011 (Hiemstra and Ten Napel, 2011). A more balanced genetic selection with faster progress in welfare traits is possible (e.g. breeding companies do have other breeds available with a lower growth potential), but this may result in a reduction of economically more important traits (Dawkins and Layton, 2012; Hiemstra and Ten Napel, 2011). Only if there is a change in market requirements would breeding companies be expected to change their selection process (Hiemstra and Ten Napel, 2011). In some regions of Europe, the market share of slower-growing strains has substantially increased over the past 5 years because of the change towards higher-welfare systems as a result of increased societal pressure on the negative effects of broiler production on animal welfare (Saatkamp et al., 2019). However, globally, these slower-growing broiler strains in higher-welfare systems account for only a very small part of the total broiler production volumes. 
In the next section we will first discuss some aspects of broiler behaviour and space use. Section 3 discusses important welfare problems in broiler production for the on-farm stage, Section 4 discusses the relationship between growth rate and welfare of broiler chickens, and Section 5 discusses environment and management factors affecting broiler welfare.

\section{Broiler behaviour and space use}

Broiler chickens are usually housed in large groups of thousands of birds, and in both mixed and sex-separated groups. Conventional broiler chickens can already be slaughtered at an age of 30 days (usually when thinning a flock, that is, when removing part of the chickens from the house to be slaughtered while the others are staying until a higher slaughter weight), whereas slower-growing strains may reach an age of 49 to over 70 days of age (in case of organic broiler production or Label Rouge production) (e.g. Vissers et al., 2019; Bracke et al., 2019a). This means that these are young birds that will never become adults (which would take around 17-20 weeks), and their behaviour will be juvenile too, that is their sexual and agonistic behaviour will never be fully developed.

Adequate use of space may enable the full performance of natural behaviours. However, space use in commercial broiler houses is often not evenly distributed, with broiler chickens clustering close to the walls from the first day of age onwards (BenSassi et al., 2019a; Leone and Estevez, 2008a). This can be due to their preference to seek protection from perceived predation both from the walls and conspecifics while resting, but it may increase the risk for welfare issues, such as disturbance of resting birds due to movements from the periphery to the central area with feeders and drinkers (Ventura et al., 2012; Buijs et al., 2010), increasing temperature at bird level resulting in heat stress (Ventura et al., 2012), and deteriorating litter quality resulting in contact dermatitis and dirty plumage (BenSassi et al., 2019a). Insight in factors determining space use, neighbour distances and distribution of broilers may help to find ways to promote better use of the available space in commercial houses and thus broiler welfare.

Studies under experimental conditions in fast-growing broiler chickens to determine the effects of group size, pen size and stocking density on the distribution of the chickens in the pen and the use of space showed that pen size had the largest effect on movement and space use patterns, irrespective of group size and stocking density. With increasing pen size, activity, neighbour distances and space use increased, thus chickens used larger space when available (Leone and Estevez, 2008a, b; Leone et al., 2010; Mallapur et al., 2009). Physical barriers of other animals played a role at higher-stocking densities, leading to lower neighbour distances (Leone and Estevez, 2008b). The authors suggested that two motivations play a role in establishing neighbour distances: 
on one hand, other chickens offer protection and thus low neighbour distances might be preferred, while on the other hand, resource competition may increase the distance between chickens in a group (Leone et al., 2010). As high-stocking densities have been found to be aversive to broiler chickens, this motivation may also play a role when stocking densities increase (Buijs et al., 2011b), which will be discussed in more detail below. Buijs et al. (2011b) also showed that nearest neighbour distances varied according to the type of behaviour the broilers were performing. Chickens that were eating and drinking showed higher neighbour distances than birds that were foraging, preening or adjusting their sitting or lying posture, or showing other behaviour (which included resting). This is in line with the suggestion of Leone et al. (2010) that the motivation to seek protection plays a role, as chickens are vulnerable to predation when showing behaviours such as resting, dustbathing and preening, which involve periods of time during which the eyes are closed. Apart from seeking social protection during these behaviours (by sitting more close to conspecifics), broilers have also been shown to perform these behaviours more often in areas with artificial protection, such as panels or close to walls (Cornetto and Estevez, 2001). Moreover, providing cover (by using panels) resulted in a better distribution of broiler chickens over the pen (Cornetto et al., 2002), with the largest effects seen in small groups ( 5 versus 10 or 20 broilers per group) (Leone et al., 2007). This was in line with the hypothesis that broilers in small groups perceive that they are more vulnerable to predation because of reduced social protection.

Similar effects on the spatial distribution of chickens over the pen were found with barrier perches (panels with perches on top) (Ventura et al., 2012). Moreover, both cover panels and barrier perches decreased neighbour disturbances (Ventura et al., 2012; Leone et al., 2007), and also aggression decreased significantly when barrier perches were provided (Ventura et al., 2012). The latter might be due to the better distribution of resting birds over the pen and reducing the open space (Ventura et al., 2012), as it has been shown that aggressive behaviours are mainly observed in the open central space in the pen (Pettit-Riley et al., 2002). Also in commercial flocks clustering of chickens around structures placed in the central area of the house has been observed, for example, when bales of straw or wood shavings were provided (de Jong and Gunnink, 2019; Bailie et al., 2013) although these studies did not find any positive effects on the incidence of disturbance and aggression.

Although interesting from a behavioural point of view, results of experimental studies on effects of enclosure size and group size in broiler chickens on space use are difficult to translate to the commercial situation where broilers are housed in much larger groups. However, providing structures probably improves bird distribution and may reduce negative behaviours, as well as have other potentially positive effects, which will be discussed in the section on environmental enrichment. 


\section{Welfare issues in broiler chicken production: leg health, heat stress and behavioural restrictions}

Impaired leg health is considered one of the most severe welfare problems related to the on-farm stage of broiler chickens (EFSA, 2010). Leg health includes lameness (infectious, degenerative and developmental disorders) and contact dermatitis on the feet and hocks (footpad dermatitis and hock burn) (Bradshaw et al., 2002). Other welfare issues are impaired health, including metabolic diseases, which may result in mortality and/or the application of medication, thermal discomfort (mainly heat stress) and so-called behavioural restrictions. The latter refers to environmental and physical restrictions to perform the full range of natural chicken behaviour (EFSA, 2010). For a detailed description of leg disorders and the effect on broiler welfare we refer to elsewhere in this chapter. Here we will only give some information on the prevalence in commercial broiler systems, if known, and discuss the relationship with growth rate.

\subsection{Prevalence of welfare issues in different broiler production systems}

Walking ability is usually assessed in commercial flocks using the gait score, which assigns a score between 0 and 5 (perfect to unable to walk) (Kestin et al., 1999). In the literature over the past 10 years, the estimated prevalence of a moderate to severe defect, that is a gait score of 3 and higher, may be as high as $30 \%$ of the chickens in conventional indoor systems with fast-growing breeds (e.g. Bassler et al., 2013; Sanotra et al., 2001; Knowles et al., 2008) and recent figures illustrate that it can even be higher. In a recent Norwegian study, $24 \%$ of the chickens (Ross 308 ) had a gait score of 3 and higher, but this was at a relatively young age (29 days) due to the low slaughter age in Norway (Kittelsen et al., 2017). A recent study in the United States including various fast-growing breeds showed that an impaired walking ability was found in more than $22 \%$ of the chickens in flocks slaughtered at a light body weight $(2.2 \mathrm{~kg})$ and more than $34 \%$ of the chickens slaughtered at a high body weight (over $3.6 \mathrm{~kg}$ ) (Opengart et al., 2018). In higher-welfare broiler systems fewer broilers have an impaired walking ability. In Germany, 25\% of broilers in a conventional system (fastgrowing breed (Ross 308), no enrichment, maximum stocking density of $35 \mathrm{~kg} /$ $\mathrm{m}^{2}$ ) showed an impaired walking ability compared to $1 \%$ of broilers in a higherwelfare system (slower-growing breed (Cobb Sasso 175A), enrichment and covered veranda, maximum stocking density of $29 \mathrm{~kg} / \mathrm{m}^{2}$ ) (Bergmann et al., 2016). A Dutch study compared conventional flocks with fast-growing Cobb 500 and Ross 308 breeds (no enrichment, 39-42 kg/m²) with indoor housed slow-growing strains (Hubbard JA757) with environmental enrichment and a 
lower stocking density $\left(<38 \mathrm{~kg} / \mathrm{m}^{2}\right)$ and found more than $60 \%$ of the chickens with a moderate to severe defect (gait score 3 and higher) in conventional flocks versus less than $20 \%$ in the higher-welfare system (Gerritzen et al., 2019). These figures indicate variation between systems and room for improvement in all systems, but especially in the conventional indoor systems.

Three types of contact dermatitis can be observed in broiler chickens: footpad dermatitis, hock burn and breast burn or breast irritation (Haslam et al., 2007). Usually, prevalence of footpad dermatitis is higher as compared to hock burn and breast burn. In a recent study in the United States, prevalence of 27\% and $1.5 \%$ for mild and severe footpad dermatitis, respectively, were reported for different breeds of fast-growing broilers slaughtered at light weights (around $2 \mathrm{~kg}$ ), and $31 \%$ and 3.5\%, respectively, for fast-growing broiler breeds slaughtered at heavy weights (more than $3.6 \mathrm{~kg}$ ) (Opengart et al., 2018). Footpad dermatitis is one of the animal-based outcome data routinely collected at the slaughter plant as an indicator of broiler welfare in several European countries (Butterworth et al., 2016). This may have resulted in a decreased prevalence in recent years, for example, in the Netherlands the total footpad lesion score significantly decreased within four years after the start of monitoring from approximately 70 points to a yearly average of around 40 points (on a scale between 0 (no lesions) and 200 (all birds having severe lesions)) (de Jong, personal communication). In Denmark, monitoring started earlier; a decrease of 60 points was achieved in a period of 6 years, and on a yearly basis scores do not exceed 40 points (Kyvsgaard et al., 2013), with a drop in prevalence of severe footpad lesions from 60\% to 10\% (European Commission, 2016). In higher-welfare broiler systems a significantly lower prevalence of footpad dermatitis is generally found. Bergmann et al. (2016) reported a prevalence of $16.5 \%$ and $2.5 \%$ around slaughter age for broilers in conventional systems (fast-growing Ross 308 breed, stocking density of $35 \mathrm{~kg} / \mathrm{m}^{2}$ ) and a higherwelfare concept (slower-growing Cobb Sasso 175A breed, covered outdoor and enrichment, stocking density of $\left.29 \mathrm{~kg} / \mathrm{m}^{2}\right)$, respectively. Similar differences were found in two Dutch studies (22\% and 4.8\%, respectively (Ellen et al., 2012), and around $45 \%$ and $0 \%$, respectively, in conventional versus higher-welfare systems (Gerritzen et al., 2019)). A comparison of RSPCA freedom food flocks (slow-growing broilers, stocking density maximum $30 \mathrm{~kg} / \mathrm{m}^{2}$, environmental enrichment) with the industry standard Red Tractor (indoor housing, fastgrowing breeds, no enrichment, stocking density $38 \mathrm{~kg} / \mathrm{m}^{2}$ ) showed that Freedom Food flocks had on average $3.5 \%$ footpad dermatitis compared to $6.5 \%$ for the conventional flocks (RSPCA, 2006). An exception is the organic broiler farms, where a higher prevalence of footpad dermatitis has been found than on conventional farms (Lund et al., 2017), or a higher variation is observed. For example, in France a prevalence between $4.6 \%$ and $39.6 \%$ was observed, depending on the farm type (mobile houses had a higher prevalence) and time 
of visit. This variation might be due to the varying conditions in the outdoor range on organic farms and due to inadequate ventilation in mobile houses causing wet litter (Souillard et al., 2019).

Recent figures on the prevalence of hock burn and breast irritation are scarce. Bassler et al. (2013) reported on average $7.9 \%$ of broilers with hock burn on European farms. Bergmann et al. (2016) reported superficial hock lesions in $33 \%$ and $20 \%$ of the broilers in German conventional (indoor, fast-growing Ross 308 breed, stocking density $35 \mathrm{~kg} / \mathrm{m}^{2}$ ) and higher-welfare systems (slowgrowing Cobb Sasso 175A breed, enrichment and veranda, stocking density of $29 \mathrm{~kg} / \mathrm{m}^{2}$ ), respectively, and $1.8 \%$ severe hock burn in the conventional system close to slaughter age. When comparing RSPCA freedom food flocks with flocks housed according to the conventional system in the United Kingdom, the RSPCA flocks had on average 3.5\% hock burn whereas the conventional flocks had 19\% (RSPCA, 2006). A Dutch study reported that $24 \%$ of broilers in conventional flocks had hock burn at slaughter, whereas in the higher-welfare concept this was only observed in 1.1\% of the chickens (Ellen et al., 2012), and more recently, no severe hock burn was observed in Dutch higher-welfare concept flocks (enrichment, stocking density lower than $38 \mathrm{~kg} / \mathrm{m} 2$, slowergrowing Hubbard JA757 breed) compared to around 10\% for the conventional indoor flocks using Ross 308 or Cobb 500 breeds (Gerritzen et al., 2019). Thus, hock burn figures illustrate a similar trend as footpad lesions, with lower levels of hock burn present in higher-welfare systems than in conventional systems. With respect to breast irritation, Gerritzen et al. (2019) found 0\% in the higherwelfare system and in less than $5 \%$ of the broilers in conventional indoor systems. In an older study of Haslam et al. (2007) breast burn was observed in less than $1 \%$ of broilers, but Allain et al. (2009) reported breast burn in $15.8 \%$ of broilers with high variation between flocks. They reported an effect of genotype and stocking density with a higher prevalence in the fast-growing broilers and a high stocking density as compared to flocks with slow-growing broilers or a lower stocking density. Taken together, all types of contact dermatitis (footpad dermatitis, hock burn and breast burn) can be present on broiler farms with a lower risk in higher-welfare concepts.

Mortality is related to health, but, not all health issues relevant for welfare are properly captured by mortality figures, although these at least give an indication. With respect to total mortality, the figures show some variation, being sometimes lower in higher-welfare systems, but not always. However, calculated as mortality per day, mortality figures are usually lower in higherwelfare systems. The RSPCA reported figures of 1.8\% for their Freedom Food concept versus $5.1 \%$ for conventional (RSPCA, 2006). Bassler et al. (2013) reported an average mortality rate of $3.6 \%$ on conventional farms in Europe. Bergmann et al. (2016) reported mortality figures that were comparable in indoor conventional and higher-welfare flocks (3.5\% and 3.4\%, respectively), 
but in the higher-welfare systems broilers had a longer rearing period. In a Dutch study, the average mortality over the whole rearing period was higher in the higher-welfare system than in the conventional system (3.4 vs. $2.7 \%$ ), but this was calculated over a rearing period of 56 days for conventional versus 39 days, respectively, for higher-welfare systems (Ellen et al., 2012). However, in a more recent Dutch study, mortality figures of $3.7 \%$ and $1.9 \%$ were found for conventional indoor and higher-welfare flocks, respectively (Gerritzen et al., 2019). Souillard et al. (2019) reported mortality levels between $2.7 \%$ and $3.1 \%$ on organic farms in France (excluding mortality caused by predation), depending on farm type, but it should be kept in mind that these were registered over a rearing period of 86 days.

Antibiotics-usage data in the Netherlands in 2018 showed that antibiotic treatments are applied more at farms with fast-growing than with slow-growing breeds, with on average $31 \%$ of the farms with fast-growing breeds applying any antibiotic treatment versus $9 \%$ of the farms with slow-growing strains, and preventive treatments not being allowed (Avined, 2019). Although antibiotics usage is not necessarily linked to health, these data nevertheless indicate that health problems are less prevalent on farms with slower-growing strains.

With respect to the welfare issue of behavioural restrictions, broilers in a higher-welfare system in Germany (maximum stocking density of 29 kg/ $\mathrm{m}^{2}$, slower-growing Cobb Sasso 175A strain and enrichment provided) were significantly more active during the rearing period than fast-growing Ross 308 broilers in an indoor system (maximum stocking density $35 \mathrm{~kg} / \mathrm{m}^{2}$ ) (Bergmann et al., 2017). As far as we know, there are no other publications comparing the behaviour of broiler chickens in conventional versus higher-welfare systems, which indicates that there is a need for studying behaviour of broiler chickens in different production systems.

When comparing conventional indoor-housed broiler flocks with flocks housed in higher-welfare systems, it is often not possible to attribute differences to breed, environmental or management factors, which are normally confounded in such comparative studies. What we know about the separate effects of breed, management and environmental aspects on broiler welfare will be further discussed below.

To date (modern colony) cage systems for broilers have not been studied in great detail. In cage systems broiler welfare may be compromised as compared to conventional indoor floor systems, because of movement restriction, poor bone strength due to lack of exercise, the inability to perform natural behaviours such as dust bathing and scratching, relatively high-stocking densities (which are usually higher as compared to indoor floor systems), and, although depending on the floor type, the risk for skin and leg injuries (Shields and Greger, 2003). Experts assign low welfare scores to these cage systems (Bracke et al., 2019a). In contrast, producers stress that there might be advantages of the plastic floors 
in the modern colony cages with respect to heat dissipation and the risk for footpad lesions and hock burn, which however requires further study before drawing any conclusion about possible welfare advantages.

\section{The relationship between growth rate and broiler welfare}

\subsection{Effects of growth rate on leg health, mortality and heat stress}

Few studies are available comparing fast- and slow-growing broiler breeds housed under similar conditions. Van Middelkoop et al. (2002) compared one fast- (Cobb) and one slow-growing (Hubbard) breed that were reared until similar slaughter weight and housed under similar semi-commercial conditions. A significantly lower mortality rate was found in the slow-growing breed than in the fast-growing one (1.5\% vs. 5.6\%). This was mainly due to heart and circulation problems in the fast-growers and these were nearly absent in the slow growers. In addition, slow growers had a significantly better walking ability (13.1\% vs. $43.4 \%$ of the birds had a gait score of 3 and higher for the slow vs. fast-growing broiler strain), and significantly better scores for footpad dermatitis, hock burn and breast irritation (proportion of birds with severe footpad dermatitis $0 \%$ vs. $9.8 \%$, hock burn $11.5 \%$ vs. $44.9 \%$, breast irritation $10.1 \%$ vs. $56.6 \%$ for slow- vs. fast-growing breed). Similar effects for mortality, gait score, breast irritation, footpad dermatitis and hock burn were found in a second study comparing one slow- (Hubbard) and fast-growing Ross breed, both in two similar semi-commercial housing conditions (with and without an outdoor range) (Rodenburg et al., 2004). For example, severe footpad lesions were found in $6 \%$ and $16 \%$ of fast-growing broilers (housed indoor and with outdoor access, respectively), compared to $0 \%$ and $0.5 \%$ in slow-growing birds (housed indoor and with outdoor access, respectively) (Rodenburg et al., 2004). Recently, Dixon (2020) compared three fast-growing strains from the main commercial broiler companies with one slow-growing strain (Hubbard JA757) housed under similar conditions. With respect to mortality, the slowgrowing strain and one fast-growing strain had significantly lower mortality levels than the other two fast-growing strains. Moreover, the slow-growing strain had lower proportion of hock burn and significantly better locomotion scores, for example, around $10 \%$ of the slow-growing strain had a gait score 3 (moderate defect) as compared to around $30-40 \%$ for the three fastgrowing strains. Footpad dermatitis scores were low in all strains and did not significantly differ between the strains in that particular study. Slow-growing broilers are thought to be less susceptible to heat stress than conventional fast-growing breeds (de Jong et al., 2012a), but as far as we know there are no data to illustrate this. 
Although differences exist between different types of slow-growing strains with respect to the welfare issues discussed here, these seem to be small, especially as compared to the differences between fast- and slower-growing broiler strains (Louton et al., 2019; Rauch et al., 2017). Taken together with the (confounded) system comparisons these few studies indicate that the use of slower-growing broiler strains, indeed, explains part of the lower risk for leg disorders and impaired health in higher-welfare systems.

\subsection{Effects of growth rate on broiler behaviour}

Conventional fast-growing broiler chickens are usually rather inactive with a peak in activity around the fourth week of age (Ventura et al., 2012; Bizeray et al., 2002) and a sharp decrease in activity with increasing age thereafter (Arnould and Faure, 2003; Wallenbeck et al., 2016; Hall, 2001; Shields et al., 2005). This is in part due to their housing conditions, such as the increasing stocking density $\left(\mathrm{kg} / \mathrm{m}^{2}\right)$ with age, preventing the birds from performing undisturbed and active behaviours, and the lack of stimulation from the environment (absence of environmental enrichment, low light intensities, low litter quality) (de Jong et al., 2012a; EFSA, 2010), which will be discussed in the following paragraphs. But the low-activity levels are also due to physical restrictions such as leg health problems and heat stress when these birds try to be active (Bokkers and Koene, 2004). It has been suggested that the high and efficient growth rate prevents fast-growing broilers from becoming active, whereas they are still motivated to perform activities like walking, dust bathing, scratching and jumping onto perches or other elevated structures (Bokkers et al., 2007).

Comparisons of time budgets of broiler strains with different growth rates generally show higher activity levels in slow-growing as compared to fastgrowing strains (Nielsen et al., 2004; Branciari et al., 2009; Dal Bosco et al., 2010; Malchow et al., 2019a; Steenfeldt et al., 2019; Wallenbeck et al., 2016; Dixon, 2020). Under similar housing conditions, both fast- and slow-growing strains show a decreased activity and decreased foraging behaviour with increasing age (Bokkers and Koene, 2004; Wallenbeck et al., 2016), although the decline in activity in slow-growing strains has been shown to be more gradual than in the fast-growing strains (Nielsen et al., 2004). Using female broilers in a spacious environment with perches, Bokkers and Koene (2003) observed that fast- and slow-growing Hubbard broilers performed the same behaviours but with different time budgets. Slow-growing broilers perched, walked and scratched more than fast-growing broilers, and fast-growing broilers were sitting more on the floor, eating and drinking. A follow-up experiment indicated that physical ability was the determining factor for activity in heavy broiler chickens, whereas motivation did not seem to be affected. The authors tested broilers weekly in runway tests, where they could receive a 
food reward. They manipulated motivation by applying short- $(3 \mathrm{~h})$ and longterm (24 h) feed deprivation and tested both fast- and slow-growing Hubbard broilers until 12 weeks of age (when both breeds reached a high body weight to include possible physical restrictions). Their results indicated that motivation determined the latency to walk and the walking speed in the runway of broilers with a low body weight, while physical ability determined latency and walking speed in broilers with a high body weight (Bokkers and Koene, 2004). In a later study also Wallenbeck et al. (2016) showed that fast-growing Ross 308 broilers spent more time sitting, drinking and eating, whereas slow-growing Rowan Ranger broilers showed more active behaviours such as foraging and perching up to 12 weeks of age.

There are different slow-growing broiler strains that may potentially differ in their behaviour, and between-breed comparisons of behaviour in slow-growing broiler strains is reported in a few studies. Rayner et al. (2019) showed that, when comparing one fast- and two slow-growing broiler breeds at stocking densities of 30 and $34 \mathrm{~kg} / \mathrm{m}^{2}$ under commercial conditions, both slow-growing breeds performed significantly more 'positive behaviours' as compared to the fast-growing breed, also at the higher stocking density. They defined 'positive behaviours' as playful, comfort-related, exploratory-related or safety-related behaviours. Torrey et al. (2019) compared three slow-growing strains and one fast-growing strain with respect to their behavioural time budgets. All strains were housed in enriched pens with a stocking density of $30 \mathrm{~kg} / \mathrm{m}^{2}$. The fast-growing strain spent significantly more time sitting and less time standing and walking at a similar age, and at a similar weight the fastgrowing strain spent more time sitting and less time walking than the slowgrowing strains. They observed no differences in behaviour between the three slow-growing strains.

Thus, slow-growing broiler strains are generally more active as compared to fast-growing strains and there are indications that they also show more species-specific behaviours, but differences between different slow-growing breeds appear to be small or absent.

\section{Effects of environment and management on welfare}

This section discusses the effects of management practices and environmental conditions on broiler welfare. Although single factors are discussed one by one, it should be noted that these factors often interact (Averos and Estevez, 2018) and it is, therefore, sometimes difficult to disentangle the effect of a specific management practice or environmental factor on welfare. In addition, most studies focus on the effect of environmental factors on the welfare of conventional, fast-growing broiler strains. Where available we will include information on slower-growing broiler strains. 


\subsection{Hatching environment}

The majority of broiler chicks hatch at the hatchery and are transported to the broiler farm after pulling (being collected from the hatching machine), when the majority of chicks have hatched, and after applying management procedures such as removal of second-grade chicks, sexing and vaccinating. As the chicks do not hatch all at the same time but rather over a period of 24-48 $\mathrm{h}$, the period between hatching and arrival at the broiler farm may last up to $72 \mathrm{~h}$ for chicks that hatched first. During this period, broiler chickens usually do not receive food and water (Willemsen et al., 2010). Although yolk sac reserves should, in theory, provide sufficient energy for survival (Mitchell, 2009), it has been suggested that this so-called post-hatch food and water deprivation may have negative effects on broiler welfare (since these birds have been selected for very rapid growth from an early age and may be less well able to deal with a negative energy balance) (Willemsen et al., 2010). A meta-analysis of the literature on the effects of this post-hatch feed and water deprivation indeed showed that a period of post-hatch food and water deprivation of more than $36 \mathrm{~h}$ resulted in significantly increased mortality not only at a young age but also up to the slaughter age, suggesting that welfare may be compromised in the longer term too, in addition to thirst and hunger in the initial post-hatch period (de Jong et al., 2017). Apart from the post-hatch feed and water deprivation, hatching conditions in itself (de Gouw et al., 2017) and the resulting handling and transport of day-old chicks are probably stressful (Jacobs et al., 2017; Hedlund et al., 2019). For example, chicks are exposed to high concentrations of dust and pathogens in the hatcher, to a high noise level, darkness and disinfected with formaldehyde (de Gouw et al., 2017).

To overcome these stressful events around hatching and the possible longterm negative consequences on broiler welfare, systems have been developed that enable hatching in the broiler house. In these systems, eggs that have been incubated for 18 days (out of the 21 needed for hatching) are transported to the broiler farm, where the eggs are placed in trays, boxes or in the litter. The chicks are provided with feed and water immediately after hatching. There are also systems where broilers receive feed and water in the hatchery and are transported to the broiler farm thereafter. Until now, very limited research has been done on these practices, but it has been shown that broiler welfare may benefit from such alternative hatching practices. A comparison of on-farm hatched versus hatchery-hatched chickens showed that on-farm hatched flocks had a better litter quality and less footpad dermatitis as compared to hatcheryhatched flocks (de Jong et al., 2019). Broiler chicks that received feed and water immediately after hatching and subjected to handling and transport were less fearful at 30 days of age than broiler chicks that were post-hatch feed and water deprived and subsequently handled and transported, whereas the response at 
3 days of age was the other way round (Hollemans et al., 2018). This suggests that post-hatch feed deprivation may have long-term effects on broiler welfare that merit further study.

\subsection{Stocking density}

The effects of stocking density on broiler welfare were reviewed by de Jong et al. (2012a), and we concluded that there was no critical density from which broiler welfare is decreased, as this seemed to vary between studies and welfare indicators. However, it was also concluded that broilers prefer stocking densities that were lower than the maximum densities allowed in the EU legislation (39$42 \mathrm{~kg} / \mathrm{m}^{2}$ ). Broilers were highly motivated to go to areas with a lower stocking density, showing that they at least avoided commercial stocking densities (Buijs et al., 2011a). Spatial analysis suggested that broilers at stocking densities from $15 \mathrm{~kg} / \mathrm{m}^{2}$ and higher start to experience the proximity of conspecifics as aversive at some point during the last 3 weeks of rearing. Nearest-neighbour distance analysis even showed evidence that this aversion occurred earlier in life (Buijs et al., 2011b).

Previous studies were inconsistent with respect to the effect of stocking density on most behaviours, but they all indicated that disturbances are increasing with increased stocking densities (de Jong et al., 2012a; Knierim, 2013). This increase seemed to be gradual over a wide range of stocking densities and led to shorter resting and preening durations (Buijs et al., 2011b; Buijs et al., 2010). Avéros and Estevez (2018) found an interaction between stocking density and group size on resting behaviour. In larger groups and at lower stocking densities relatively more birds were resting, which was suggested to be caused by more available space in larger groups and less disturbances caused by the low stocking density. Further, high stocking densities also resulted in a more uneven use of pen space, with a reduced use of the central area in the pen (see review in De Jong et al. (2012a)).

With increasing stocking densities, environmental temperature, humidity and litter moisture increase, especially towards the end of the growing period. It is therefore often difficult to disentangle the effects of the stocking density per se from the deteriorated environmental conditions on broiler welfare indicators, as these often coincide (de Jong et al., 2012a), especially under commercial conditions. However, it is clear from the literature that with increasing stocking density the risk for welfare problems such as impaired walking, contact dermatitis and injuries increases (de Jong et al., 2012a). This was also confirmed in more recent studies. Bailie et al. (2018b) showed that with increasing stocking density between $30 \mathrm{~kg} / \mathrm{m}^{2}$ and $36 \mathrm{~kg} / \mathrm{m}^{2}$ the prevalence of footpad lesions increased. Knierim (2013) found more footpad dermatitis at stocking densities of $35 \mathrm{~kg} /$ $\mathrm{m}^{2}$ and $40 \mathrm{~kg} / \mathrm{m}^{2}$ compared to $18 \mathrm{~kg} / \mathrm{m}^{2}$ and $25 \mathrm{~kg} / \mathrm{m}^{2}$, and a better gait score 
at $18 \mathrm{~kg} / \mathrm{m}^{2}$ compared to $35 \mathrm{~kg} / \mathrm{m}^{2}$ and $40 \mathrm{~kg} / \mathrm{m}^{2}$. BenSassi et al. (2019b) showed that a reduced stocking density decreased walking difficulties, resulted in a reduction in rejection due to injuries and in prevalence of total welfare problems ('total welfare index'). In a meta-analysis, Avéros and Estevez (2018) showed that gait scores decreased with decreasing stocking densities and in a recent review, Pedersen and Forkman (2019) also concluded that gait scores decreased and walking ability improved with decreasing stocking density. Few studies measured prevalence of tibial dyschondroplasia at different stocking densities, and no studies reported a significant effect. Many studies found an effect of stocking density on footpad dermatitis and hock burn, with a higher prevalence reported in higher stocking densities. Most of these studies were carried out in fast-growing breeds (Pedersen and Forkman, 2019).

\subsection{Litter quality}

Litter, which is referred to as bedding material mixed with faeces, can have a large impact on broiler welfare, as broiler chickens usually spend their whole life or a large part of their life (when elevated resting places are provided) on the litter floor. Good-quality bedding material absorbs moisture, provides thermal insulation, a comfortable resting place, opportunities to perform natural behaviours such as foraging and dust bathing, and affects air quality by affecting the amount of dust, humidity, endotoxins and ammonia in the air. It depends on the particular housing system and country whether or not broiler chickens start with new and fresh bedding material upon placement, or whether or not litter is re-used during several production rounds (and a top dressing of, for example, wood shavings is added when a new production cycle is started) (de Jong et al., 2012a). Several bedding materials are used in practice, dependent on local traditions and availability. Frequently used bedding materials are wood shavings, peat, sawdust, (chopped) straw, straw pellets, sand and rice hulls (e.g. Shepherd et al., 2017). The bedding material is mixed with faeces during the growing period and close to slaughter age the major part will consist of faecal material (dependent on the amount of substrate provided at the placement of the chickens). The litter quality will depend on the quality of the faeces, climate in the house, activity of the chickens and incidents such as leakage of drinkers.

Usually litter quality deteriorates during the production cycle (e.g. BenSassi et al., 2019a; Wilhelmsson et al., 2019) due to increased amount of faeces and increasing stocking density and due to inactivity of the birds. Hence, farmer management (including nutrition) is very important to keep the litter in a good condition (i.e. dry and loose). Wet or sticky litter increases dirtiness of the chickens (BenSassi et al., 2019a); increases the risk for footpad dermatitis, hock burn (Shepherd et al., 2017) and breast irritation; leads to cold stress 
(due to reduced insulation capacity) (de Jong et al., 2014); and is related to an increased condemnation rate at slaughter (BenSassi et al., 2019a), probably due to infection with bacteria present in the litter (Shepherd et al., 2017). A farmer has several options to control litter quality. A thin layer of litter has been suggested to reduce the risk for footpad dermatitis, although this may depend on the floor type and presence of underfloor heating (Shepherd et al., 2017). To prevent footpad dermatitis due to a low litter quality, it is advised to increase heating and ventilation to keep the litter dry and loose (De Jong et al., 2013). The prevalence of footpad dermatitis is related to the quality of the bedding material, and most likely to its capacity to absorb moisture. For example, straw bedding increases the risk of footpad dermatitis compared to peat and wood shavings (Kyvsgaard et al., 2013; Shepherd et al., 2017). Also, the quality of the feed is important for litter quality (Swiatkiewicz et al., 2017) and, for example, gut health problems leading to diarrhoea may also lead to a deteriorated litter quality. Scratching the litter will keep it dry and loose, and promote drying. Thus, also bird activity may affect litter quality. Lowering the stocking density in the house will increase litter quality, because it reduces the amount of faeces and increases bird activity (de Jong et al., 2012a).

Broiler chickens in conventional systems usually only have the litter floor to perform behaviours such as dust bathing and foraging. Compacted, wet litter or litter covered with a crust will not be suitable for these behaviours, and in this way may hamper the birds to perform their natural behaviours. Furthermore, chickens show preferences for dust bathing materials and bedding material with small particles such as peat or sand would be better suitable to perform this behaviour as compared to, for example, straw bedding (Shields et al., 2004; Baxter et al., 2018a). While on the one hand, dry and loose litter may have positive effects on broiler welfare, on the other hand, this creates higher dust levels which can be a risk for bird's health especially with low ventilation rates (e.g. early in the production cycle or in the cold season) (de Jong et al., 2012a). This will be discussed further below.

\subsection{Air quality}

Air quality refers to the concentration of dust, endotoxins and gases in the air, of which ammonia is the most important, and to the thermal environment (temperature and humidity). Young chickens are not able to maintain their body temperature at the appropriate level and an appropriate temperature should therefore be provided, whereas a too high environmental temperature in the final stage of the rearing period may cause heat stress, especially in fastgrowing chickens (de Jong et al., 2012a; EFSA, 2010). Ventilation is important to keep the humidity at the required level to prevent wet litter and to provide a comfortable environment. In wet and cold seasons low ventilation rates, to 
keep the temperature at the desired level, may result in wet litter and higher levels of footpad dermatitis (de Jong et al., 2012b, 2013). Misting systems can be used during hot summer days to reduce heat stress, but these also increase the moisture level in the house and may thus cause a deteriorated litter quality. The distribution and behaviour of broilers in the house is indicative of the thermal environment, with broilers showing huddling when it is too cold or draughty, and panting behaviour when the environmental temperature is too high (Welfare Quality, 2009).

Dust and ammonia clearly have negative effects on broiler welfare. High ammonia concentrations irritate the eyes, throat and mucous membranes, leading to eye damage, increased disease prevalence and a reduced body weight gain in broilers. When given a choice, broiler chickens avoided concentrations of above $10 \mathrm{ppm}$, which are commonly present in poultry houses (Jones et al., 2005). The main source of ammonia is the faeces (David et al., 2015a). Ammonia concentrations in broiler houses is affected by many factors such as ventilation, humidity, temperature, litter quality, moisture and $\mathrm{pH}$, feed composition and stocking density (de Jong et al., 2012b; David et al., 2015a).

Both the environment, for example, the litter and feed, and the broilers themselves produce dust. Dust contains both organic and inorganic matter. The type of bedding material affects the amount of dust produced as well as litter quality and bird activity. Dust clearly has a negative effect on broiler health. Airborne micro-organisms are frequently attached to dust particles and these may be directly pathogenic or they may release toxins, increasing the susceptibility of the chickens to non- or low-pathogenic micro-organisms. Because of the antigenic effects/capacity of dust it may activate the immune system, leading to hypersensitivity and respiratory diseases (David et al., 2015b). Although there is no doubt that dust and the attached micro-organisms have a negative effect on the health of the chickens (David et al., 2015b; de Jong et al., 2012b), it is not clear to what extent broilers' health is affected by dust, as broiler chickens are slaughtered at a very young age. Ventilation and humidity are important to control dust levels in broiler houses (de Jong et al., 2012b).

\subsection{Light}

Light has different aspects that can affect broiler welfare: intensity, photoperiod (the number of light and dark hours within the $24 \mathrm{~h}$ cycle), source (artificial or natural light) and spectrum. We will discuss these aspects separately below, but it should be noted that the different aspects are usually confounded in studies as well as under commercial conditions. 


\subsubsection{Light intensity}

Minimum light intensity has been regulated by legislation; for example, the EU Broiler Directive (European Commission, 2007) stated that a minimum level of 20 lux at bird height is required at $80 \%$ of the floor area in the broiler house. Usually during the first days of life a higher light intensity is provided to enable the chicks to find feed and water, according to recommendations of the breeding companies. As reviewed by de Jong et al. (2012a), broilers seem to prefer brighter light when being active and more dim light when resting, but there is remarkably little effect of different light intensities on the time performed on specific behaviours (reviewed in De Jong et al., 2012a), apart from a higher overall activity level with increasing light intensity (e.g. Blatchford et al., 2012; Rault et al., 2017). More important seems to be the difference between the light and the dark period. A low contrast in light intensity between the light and dark periods dampened behavioural rhythms, with broilers being more active during the photophase and less active during the scotophase when a high contrast between the light and dark periods was provided (Alvino et al., 2009a; Blatchford et al., 2012). In addition, it has been shown that high light intensities improve the levels of synchronisation of activities during the photophase and uninterrupted resting during the scotophase (Alvino et al., 2009 b) in broilers. Light intensities lower than 5 lux (in both the photoperiod and scotoperiod) cause an increased eye weight and larger eyes, thus affecting eye morphology (Blatchford et al., 2012; Deep et al., 2013; Rault et al., 2017). The majority of studies showed that light intensity did not affect gait score, immunity and mortality (reviewed in De Jong et al. (2012a) and for leg health in Pedersen and Forkman (2019)) whereas some authors found fewer footpad lesions with increasing light intensity (Pedersen and Forkman, 2019; Deep et al., 2013), which might be related to the increased activity under high light intensities.

\subsubsection{Light programme}

Quite a number of studies focussed on the effect of light programmes on broiler production and health. Usually, during the first days of life broilers are provided with continuous or near-continuous light to enable them to find feed and water, and after a week a light programme is started. This is sometimes regulated by legislation, for example, the EU Broiler Directive states that broiler chickens must have a dark period of $6 \mathrm{~h}$ per $24 \mathrm{~h}$, of which $4 \mathrm{~h}$ of uninterrupted dark period is mandated (European Commission, 2007). Pedersen and Forkman (2019) recently reviewed the effect of light programmes. The majority of studies reviewed reported a significant effect of light programme on leg health. Although many different light schedules were studied, in general, intermittent lighting schedules promoted leg health as compared to continuous lighting 
(defined as $23 \mathrm{~h} \mathrm{~L}$ (light):1 h D (dark)). Gait score and leg disorders were most affected by the light programme with better scores when intermittent lighting schedules were applied (Pedersen and Forkman, 2019; Karaarslan and Nazligul, 2018). Broilers provided with sufficiently long dark periods generally have fewer health problems, including metabolic diseases and an abnormal eye development (reviewed in De Jong et al. (2012a)). A limited number of studies examined the effect of light programmes on broiler behaviour. Schwean-Lardner et al. (2012) studied uninterrupted dark periods of $10 \mathrm{~h}, 7 \mathrm{~h}$, $4 \mathrm{~h}$ and $1 \mathrm{~h}$ per $24 \mathrm{~h}$ at $27-28$ and $42-43$ days of age. They found that time spent on standing, walking, feeding, preening, stretching, dust bathing and litter pecking decreased with increasing day length at both ages, both during the photoperiod and as the daily average (of $24 \mathrm{~h}$ ). Running was not observed with $1 \mathrm{~h}$ darkness at both ages and dust bathing was not observed with $1 \mathrm{~h}$ darkness at 42-43 days of age. Furthermore, long photoperiods resulted in a reduced responsiveness to an observer. They concluded that welfare was compromised in near-continuous lighting, whereas long dark periods of $10 \mathrm{~h}$ did not show any advantage, based on behavioural observations, compared to dark periods of $7 \mathrm{~h}$. A recent study of Sun et al. (2017) confirmed that comfort behaviours were less prevalent under near-continuous lighting ( $23 \mathrm{~h} \mathrm{~L}: 1 \mathrm{~h} \mathrm{D}$ ) versus $16 \mathrm{~h} \mathrm{~L} 8 \mathrm{~h}$ $\mathrm{D}$ and an interrupted schedule of $6 \mathrm{~L}: 2 \mathrm{D}: 2 \mathrm{~L}: 4 \mathrm{D}$. Splitting the scotoperiod, that is, two periods of $4 \mathrm{~h}$ darkness per $24 \mathrm{~h}$ versus an uninterrupted dark period of $8 \mathrm{~h}$, resulted in adjusted feeding behaviours but no indications of one schedule being better than the other (Duve et al., 2011).

\subsubsection{Light spectrum}

The recent developments in the use of light emitting diode (LED) lighting in broiler houses enables farmers to provide a more complex light spectrum and adjust light spectra according to the preferences of the chickens (Archer, 2018). However, relatively little is currently known on the actual preferences of broiler chickens in relation to light composition. Chickens have a greater spectral sensitivity than humans, especially with respect to the red, blue-green and ultraviolet wavelengths (Prescott and Wathes, 1999). Huth and Archer (2015) compared broiler behaviour and health of two commercially available LED lights with compact fluorescent (CFL) lighting, and found that birds in the LED treatments showed less fearful responses and had better plumage condition, foot and hock scores than in the CFL treatment. Their LED treatments differed in output over the whole spectrum as compared to the CFL bulbs, but had especially higher outputs in the ultraviolet and infrared wavelengths. Others compared welfare aspects of broilers housed under different light spectra using LED lights. Mendes et al. (2013) found that broilers from three weeks of age onwards had a higher feed intake in white than in yellow LED light. In 
another study broilers housed under cold white light (5000 K) for the whole production period were less anxious and grew faster than broilers housed under warm white light (2700 K) (Archer, 2018). Using a preference test, Riber (2015) compared cold white light (6065 K) with warmer white light (4100 K) and found that from three weeks of age onwards broilers spent more time in the compartment with cold white light than the compartment with warm white light. Furthermore, she observed that resting behaviour was more prevalent in cold white light. These studies thus indicate that cold white light is preferable with respect to broiler welfare. However, the limited amount of studies as well as the number of spectra applied in these studies indicate that more research is necessary to determine light spectrum preferences for broiler chickens in relation to age.

\subsubsection{Light source}

Higher-welfare programmes for broiler chickens often include the provision of natural light (e.g. Saatkamp et al., 2019; Bailie et al., 2013) in broiler houses. However, little is known about the effects of natural light on broiler welfare. With natural light the whole light spectrum can be provided to the chicken and this may affect the broiler's perception of the environment. However, when natural light is provided by windows in the roofs or side-walls, the ultraviolet range may be filtered and is thus not available to/visible to the chickens (Van Niekerk et al., 2016). Broiler chickens provided with natural light show increased activity levels (Bailie et al., 2013; de Jong and Gunnink, 2019) and make better use of the environmental enrichment (de Jong and Gunnink, 2019). Bailie et al. (2013) also found better gait scores when natural light was provided. The (generally) higher light intensities provided with natural light as compared to artificial light, as well as the variation in intensity during the day, may have a large effect on broiler behaviour and potentially stimulate behavioural synchronisation (Bailie et al., 2013; de Jong and Gunnink, 2019). However, the latter aspect needs to be investigated further.

\subsection{Environmental enrichment}

The effect of environmental enrichment on broiler chicken welfare has recently been the topic of a series of studies, in addition to the ones that have been reviewed by Riber et al. (2018). Here we summarise the new findings in addition to the review of Riber et al. (2018). We also refer to the other chapters in this book where the effect of elevated resting places on poultry welfare is reviewed.

Environmental enrichment has been defined as a modification of the environment in which the animals are kept, allowing the animals to perform more of their species-specific behavioural repertoire and thus accommodating a larger range of behavioural choices (Estevez 
and Newberry, 2017). Environmental enrichments may relate to specific behavioural requirements of chickens, for example, they may meet the need for elevated resting, or for exploration pecking, and sometimes combine these different functions. In their review, Riber et al. (2018) stated that environmental enrichment can prevent abnormal behaviour, increase the positive utilisation of the environment, and increase the ability of the animals to handle behavioural and physiological challenges and thus have a positive effect on welfare. They emphasised that environmental enrichment should be biologically relevant to be effective. The majority of broiler chickens, especially fast-growing breeds in conventional systems, are housed in relatively barren environments, and despite the increased number of scientific studies reporting potentially positive effects of environmental enrichment on broiler welfare, environmental enrichment is only applied on a limited scale in practice. One reason might be that farmers and integrations often think that environmental enrichment increases production costs and thus reduces economic competitiveness (Estevez and Newberry, 2017). However, this does not take into account potential benefits of environmental enrichment on broiler health. For example, effective enrichment may reduce crowding and smothering in a flock by reducing fearfulness (Riber et al., 2018), and as a result decrease carcass condemnations (BenSassi et al., 2019b). Enrichment may also improve leg strength in broiler chickens, reducing the number of culled chickens and application of antibiotics (Kaukonen et al., 2017). And although it may increase broiler activity, most studies do not report a negative effect on feed conversion rate or growth (Riber et al., 2018). Finally, the societal demand for higher-welfare systems may lead to compensation for increased production costs, as, for example, has happened in The Netherlands, where the new retail standards involve new broiler housing concepts that require environmental enrichment (Saatkamp et al., 2019). Most studies on environmental enrichment in broiler chickens include the effect on behaviour and leg health in conventional fast-growing strains. To stimulate implementation in practice, studies on commercial farms including the effect on health, antibiotic treatments, carcass condemnations, feed intake and growth, and thus on economic return of production are therefore necessary, and studies should include slower-growing strains as well.

Riber et al. (2018) discriminated between 'point source enrichments', which they categorised as objects that are generally limited in size and applied on a few locations in the house, and 'complex enriched environments' that differ more radically from conventional systems, usually involving multiple enrichments or point source enrichments in combination with covered verandas or an outdoor range. Before concluding this paragraph, we discuss these two types of enrichments briefly below. 


\subsubsection{Point-source enrichment}

To meet the need for an elevated resting place for broiler chickens, perches or elevated platforms can be provided. Studies usually applied different materials for perching, such as metal, wooden or PVC pipes, being oval or round, and used different heights and shapes (e.g. A-shape, X-shaped perches). As the actual use of the perches and their effects on behaviour and other welfare indicators may differ according to the layout of the perches, it is not easy to draw conclusions on the actual use of perches and the benefits for the broilers. However, Riber et al. (2018) concluded that perch use was generally low, especially in fast-growing broilers, and this was confirmed in more recent experiments (de Jong and Gunnink, 2019; Bailie et al., 2018a; Bench et al., 2017; Malchow et al., 2019a; Bergmann et al., 2017). Only a few studies tested perches in slower-growing strains with generally low use (de Jong and Van Wijhe-Kiezebrink, 2014; Bokkers and Koene, 2003; Rodriguez-Aurrekoetxea et al., 2015; Bergmann et al., 2017; Malchow et al., 2019a), although this merits further study, as perch design may have played a role. Perches may potentially provide elevated resting space for slower-growing breeds as these are not hampered as much by physical limitations, but it is important to include the effect of different shapes, design and materials on perch use. Positive effects of perches are increased activity and a better distribution of the broilers in the pen, but in general, no positive effects on foot and leg health were found (reviewed in Riber et al. (2018)). Because body weight and body conformation of broiler chickens, especially in fast-growing strains, may have a negative effect on perch use, platforms have been applied to meet the need for elevated resting places. Platforms are usually made of plastic mesh and provided at various heights with a ramp to promote platform access. Platforms were well used by both fast- and slower-growing broiler strains (Tahamtani et al., 2018; Malchow et al., 2019a,b; Kaukonen et al., 2017; de Jong and Van Wijhe-Kiezebrink, 2014; Vasdal et al., 2019), and it was suggested that platforms decrease fearfulness in broiler chickens (Tahamtani et al., 2018). The frequent use of platforms may indicate that these are better suited for broiler chickens, although platform use may also be driven by high animal densities, as they provide additional space. On the other hand, it has been shown that fast-growing breeds at $25 \mathrm{~kg} /$ $\mathrm{m}^{2}$ made better use of platforms than broilers at $35 \mathrm{~kg} / \mathrm{m}^{2}$, probably because of the 'barrier' effect of broilers on the floor at higher densities (de Jong and Goertz, 2017).

Bales of straw or wood shavings are often used as environmental enrichment in commercial practice, and studies indicate that these are generally well used (see e.g. de Jong and Gunnink, 2019; Baxter et al., 2018b, 2019; Vasdal et al., 2019; Bergmann et al., 2017). Bales may serve different functions, for example, stimulating explorative pecking, dust bathing behaviour 
because of the provision of fresh litter, resting on an elevated area as long as the bales are intact and providing protection. Panels and barriers, as indicated in the section on broiler behaviour above, provide a quiet resting area and prevent disturbance by other birds and are generally well used (Riber et al., 2018). Dark brooders are not frequently used in broiler chickens but may also provide a quiet resting area in the first two weeks (Stadig et al., 2018). Wheat, maize or other substrates provided in the litter are used to stimulate foraging behaviour, but studies did not show significant effects on leg health and activity (Vasdal et al., 2019).

Since the review of Riber et al. (2018) on several studies focussed on providing dust bathing substrates for broiler chickens, for example, in steel rings or boxes (Baxter et al., 2018a,b, 2019; Vasdal et al., 2019; Baxter and O'Connell, 2019). Different types of substrate have been tested such as oat hulls, wood shavings, straw pellets and peat moss. Such an enrichment is potentially most interesting under conditions where litter quality is insufficient to allow dust bathing and foraging behaviour, that is, in conventional systems with fast-growing breeds. Systems with slower-growing broiler strains usually apply lower stocking densities, and litter quality is much better as compared to intensive indoor systems (Ellen et al., 2012), although the effect of additional dust bathing substrates has not been tested in slow-growing broiler flocks. Both peat moss and oat hulls provided at different locations in the broiler house were attractive for broiler chickens and stimulated dust bathing and foraging behaviour (Baxter et al., 2018a,b), and oat hulls stimulated also leg health in fast-growing chickens (Baxter et al., 2018b).

Finally, pecking objects such as metal chains, strings and pecking stones are used as environmental enrichment (see Baxter and O'Connell, 2019; de Jong and Gunnink, 2019; de Jong and Van Wijhe-Kiezebrink, 2014; Bergmann et al., 2017). The extent to which these are used varied between studies and the effects on activity and other welfare indicators is unclear (Riber et al., 2018). For example, Baxter et al. (2019) found a higher use of pecking chains in their final study, combining different enrichment types, as compared to their previous study (not comparing different types of enrichment), suggesting that further study under commercial conditions is necessary.

\subsubsection{Complex environmentally enriched environments (including outdoor ranges)}

No studies have been published since the review of Riber et al. (2018) on the effects of outdoor range or indoor systems with a covered veranda on broiler welfare. Systems including an outdoor range usually include slowergrowing broiler strains (e.g. Stadig et al., 2017; Stadig et al., 2018; RodriguezAurrekoetxea et al., 2015), although fast-growing strains can also be housed 
in outdoor systems (e.g. Taylor et al., 2017a,b). Studies showed that slowergrowing strains are better capable of making use of the extra space and a more diverse environment than fast-growing broiler strains (Wilhelmsson et al., 2019; Lindholm et al., 2016; Nielsen et al., 2003). This may be related to their physical inability to make use of the additional space and resources' variability, and does not exclude that they may still be motivated to use extra space and resources and the ability to perform (certain) natural behaviours.

\subsubsection{Combining and grouping enrichments}

For commercial broiler welfare programmes, different enrichments can be combined (e.g. de Jong and Gunnink, 2019; Vasdal et al., 2019). Baxter et al. (2019) found no clear benefits of grouping enrichments, as compared to spreading the various enrichments, on behaviour and use of the various enrichment types. BenSassi et al. (2019b) compared houses with one, two or more enrichments and found that a greater environmental complexity was associated with a reduction in skin wounds, lower mortality, fewer carcass rejections due to wounds and low body weight, and fewer carcass rejections overall. More research is needed to confirm that combinations of environmental enrichment promote welfare as compared to single enrichment, as well as to determine the minimum number of enrichments that should be provided and the distribution over the house in commercial flocks.

\section{Conclusions and future trends}

In this chapter we provided an overview of welfare issues in broiler chicken production, and how these are affected by genetic, management and environmental factors. Most studies have been performed in the conventional, fast-growing breeds and are related to conditions present in intensive, conventional production systems. Studies in commercial flocks clearly indicate that the prevalence of welfare problems can be high, but variation between flocks and between production systems indicates that there are ways to reduce the prevalence of welfare problems. The increasing number of scientific studies on the effects of environmental enrichment on broiler welfare indicate that, at least in Europe and the United States (CIWF, 2018), there is a trend towards higher-welfare systems for broiler chickens. In Europe, this is also reflected by the increase in the use of slow-growing strains in these systems, such as in The Netherlands and Germany (Saatkamp et al., 2019; Bergmann et al., 2016, 2017). It is also clear that aspects such as societal pressure and market requirements will be important to improve the current situation with respect to broiler welfare (Saatkamp et al., 2019; Bracke et al., 2019a). 
The knowledge on the needs and preferences of slower-growing strains as compared to the standard, fast-growing strains is limited and clearly merits further research. With respect to broiler welfare in different production systems, experts recently assigned good welfare scores to organic systems (EU), free range (indoor and outdoor) and Label Rouge, whereas they considered broiler welfare in conventional floor systems and cage systems insufficient. Other systems like organic (US) or middle-segment concepts in The Netherlands scored in-between and were not considered as providing good welfare (Bracke et al., 2019a). However, it would be good to collect more data on system comparisons to determine the actual welfare performance of broilers in various production systems, as these are currently very scarce.

With respect to environmental and management factors, the different aspects of light, especially wavelength preferences and effects of natural light on broiler chicken welfare merit further study. Finally, little is known about the interactions of the different genetic, environmental and management aspects, which is clearly also an area for future research.

\section{Where to look for further information}

Although not very recent, the EFSA report and the update of this report (EFSA, 2010; de Jong et al., 2012a) provide a good starting point for reading. With respect to genetic selection and the relation with broiler welfare, Hiemstra and Ten Napel (2011) provide a lot of background information. The review of Bessei (2006) summarises the main welfare issues in broiler chickens. More specifically, the review by Riber et al. (2018) is a good starting point for the environmental enrichment effects on broiler welfare and the review by Pedersen and Forkman (2019) is a good starting point on the relationship between environmental enrichment and leg health. With respect to societal pressure aimed at higher welfare for broiler chickens, information on requirements in the NGO's European Chicken Commitment and US and Canada Better Chicken Commitment can be found in Anonymous (n.d.) and Anonymous, 2019, and NGO's websites report about companies stating that they will meet these requirements within a couple of years.

\section{References}

Allain, V., Mirabito, L., Arnould, C., Colas, M., Le Bouquin, S., Lupo, C. and Michel, V. 2009. Skin lesions in broiler chickens measured the slaughterhouse: relationships between lesions and between their prevalence and rearing factors. British Poultry Science 50(4), 407-417.

Alvino, G. M., Archer, G. S. and Mench, J. A. 2009a. Behavioural time budgets of broiler chickens reared in varying light intensities. Applied Animal Behaviour Science 118(1-2), 54-61. 
Alvino, G. M., Blatchford, R. A., Archer, G. S. and Mench, J. A. 2009b. Light intensity during rearing affects the behavioural synchrony and resting patterns of broiler chickens. British Poultry Science 50(3), 275-283.

Anonymous n.d. European Chicken Commitment. Available at: https://welfarecommi tments.com/europeletter/.

Anonymous 2019. Better Chicken Commitment United States \& Canada. Available at: https://welfarecommitments.com/letter.pdf.

Archer, G. S. 2018. Color temperature of light-emitting diode lighting matters for optimum growth and welfare of broiler chickens. Animal 12, 1015-1021.

Arnould, C. and Faure, J. M. 2003. Use of pen space and activity of broiler chickens reared at two different densities. Applied Animal Behaviour Science 84(4), 281-296.

Averos, X. and Estevez, I. 2018. Meta-analysis of the effects of intensive rearing environments on the performance and welfare of broiler chickens. Poultry Science 97(11), 3767-3785.

Aviagen 2019. Ross308 performance objectives. Available at: http://en.aviagen.com/ assets/Tech_Center/Ross_Broiler/Ross308-308FF-BroilerPO2019-EN.pdf. Accessed 09/10/2019.

Avined 2019. Antibioticumgebruik pluimveesector in 2018 en de trends van afgelopen jarenen de trends van afgelopen jaren. Available at: https://www.avined .nl/ sites/www.avined.nl/files/antibioticagebruik_-_sectorrap portage_2018.pdf. Accessed on 09/10/2019.

Bailie, C. L., Ball, M. E. E. and O'Connell, N. E. 2013. Influence of the provision of natural light and straw bales on activity levels and leg health in commercial broiler chickens. Animal 7(4), 618-626.

Bailie, C. L., Baxter, M. and O'Connell, N. E. 2018a. Exploring perch provision options for commercial broiler chickens. Applied Animal Behaviour Science 200, 114-122.

Bailie, C. L., ljichi, C. and O'Connell, N. E. 2018b. Effects of stocking density and string provision on welfare-related measures in commercial broiler chickens in windowed houses. Poultry Science 97(5), 1503-1510.

Bassler, A. W., Arnould, C., Butterworth, A., Colin, L., De Jong, I. C., Ferrante, V., Ferrari, P., Haslam, S., Wemelsfelder, F. and Blokhuis, H. J. 2013. Potential risk factors associated with contact dermatitis, lameness, negative emotional state, and fear of humans in broiler chicken flocks. Poultry Science 92(11), 2811-2826.

Baxter, M., Bailie, C. L. and O'Connell, N. E. 2018a. An evaluation of potential dustbathing substrates for commercial broiler chickens. Animal 12(9), 1933-1941.

Baxter, M., Bailie, C. L. and O'Connell, N. E. 2018b. Evalution of dustbathing substrate and straw bales as environmental enrichments in commercial broiler housing. Applied Animal Behaviour Science 200, 78-85.

Baxter, M., Bailie, C. L. and O'Connell, N. E. 2019. Play behaviour, fear responses and activity levels in commercial broiler chickens provided with preferred environmental enrichments. Animal 13(1), 171-179.

Baxter, M. and O'Connell, N. E. 2019. Does grouping environmental enrichments together affect the way they are used by commercially housed broiler chickens? Applied Animal Behaviour Science 210, 52-59.

Bench, C. J., Oryschak, M. A., Korver, D. R. and Beltranena, E. 2017. Behaviour, growth performance, foot pad quality, bone density, and carcass traits of broiler chickens reared with barrier perches and fed different dietary crude protein levels. Canadian Journal of Animal Science 97, 268-280. 
BenSassi, N., Averos, X. and Estevez, I. 2019a. The potential of the transect method for early detection of welfare problems in broiler chickens. Poultry Science 98(2), 522-532.

BenSassi, N., Vas, J., Vasdal, G., Averos, X., Estevez, I. and Newberry, R. C. 2019b. On-farm broiler chicken welfare assessment using transect sampling reflects environmental inputs and production outcomes. PLOS ONE 14, e0214070.

Bergmann, S., Louton, H., Westermaier, C., Wilutzky, K., Bender, A., Bachmeier, J., Erhard, M. H. and Rauch, E. 2016. Field trial on animal-based measures for animal welfare in slow growing broilers reared under an alternative concept suitable for the German market. Berliner Und Munchener Tierarztliche Wochenschrift 129, 453-461.

Bergmann, S., Schwarzer, A., Wilutzky, K., Louton, H., Bachmeier, J., Schmidt, P., Erhard, M. and Rauch, E. 2017. Behavior as welfare indicator for the rearing of broilers in an enriched husbandry environmentd-A field study. Journal of Veterinary Behavior 19, 90-101.

Bessei, W. 2006. Welfare of broilers: a review. World's Poultry Science Journal 62(3), 455-466.

Bizeray, D., Estevez, I., Leterrier, C. and Faure, J. M. 2002. Effects of increasing environmental complexity on the physical activity of broiler chickens. Applied Animal Behaviour Science 79(1), 27-41.

Blatchford, R. A., Archer, G. S. and Mench, J. A. 2012. Contrast in light intensity, rather than day length, influences the behavior and health of broiler chickens. Poultry Science 91(8), 1768-1774.

Bokkers, E. A. M. and Koene, P. 2003. Behaviour of fast- and slow growing broilers to 12 weeks of age and the physical consequences. Applied Animal Behaviour Science 81(1), 59-72.

Bokkers, E. A. M. and Koene, P. 2004. Motivation and ability to walk for a food reward in fast- and slow-growing broilers to 12 weeks of age. Behavioural Processes 67(2), 121-130.

Bokkers, E. A. M., Zimmerman, P. H., Rodenburg, T. B. and Koene, P. 2007. Walking behaviour of heavy and light broilers in an operant runway test with varying durations of feed deprivation and feed access. Applied Animal Behaviour Science 108(1-2), 129-142.

Bracke, M. B. M., Koene, P., Estevez, I., Butterworth, A. and de Jong, I. C. 2019a. Broiler welfare trade-off: a semi-quantitative assessment of prospects for optimised welfare improvement based on an expert survey. PLOS ONE 14(10), e0222955.

Bracke, M. B. M., Vermeer, H. M. and Van Emous, R. A. 2019b. Animal Welfare Regulations and Practices in 7 (Potential) Trade-Agreement Partners of the EU with a Focus on Laying Hens, Broilers and Pigs: Mexico, Chile, Indonesia, Australia, New Zealand, Turkey and the Philippines. Wageningen Livestock Research, Wageningen.

Bradshaw, R. H., Kirkden, R. D. and Broom, D. M. 2002. A review of the aetiology and pathology of leg weakness in broilers in relation to welfare. Avian and Poultry Biology Reviews 13(2), 45-103.

Branciari, R., Mugnai, C., Mammoli, R., Miraglia, D., Ranucci, D., Dal Bosco, A. and Castellini, C. 2009. Effect of genotype and rearing system on chicken behavior and muscle fiber characteristics. Journal of Animal Science 87(12), 4109-4117.

Buijs, S., Keeling, L. J. and Tuyttens, F. A. M. 2011a. Using motivation to feed as a way to assess the importance of space for broiler chickens. Animal Behaviour 81(1), $145-151$. 
Buijs, S., Keeling, L. J., Vangestel, C., Baert, J. and Tuyttens, F. A. M. 2011 b. Neighbourhood analysis as an indicator of spatial requirements of broiler chickens. Applied Animal Behaviour Science 129(2-4), 111-120.

Buijs, S., Keeling, L. J., Vangestel, C., Baert, J., Vangeyte, J. and Tuyttens, F. A. M. 2010. Resting or hiding? Why broiler chickens stay near walls and how density affects this. Applied Animal Behaviour Science 124(3-4), 97-103.

Butterworth, A., de Jong, I. C., Keppler, C., Knierim, U., Stadig, L. and Lambton, S. 2016. What is being measured, and by whom? Facilitation of communication on technical measures amongst competent authorities in the implementation of the European Union Broiler Directive (2007/43/EC). Animal 10(2), 302-308.

Cengiz, Ö, Hess, J. B. and Bilgili, S. F. 2011. Effect of bedding type and transient wetness on footpad dermatitis in broiler chickens. Journal of Applied Poultry Research 20(4), 554-560.

CIWF 2018. What businesses have pledged to improve broiler welfare? Available at: https://www.compassioninfoodbusiness.com/our-news/2018/11/what-businesses -have-pledged-to-improve-broiler-welfare. Accessed on 13/10/2019.

Cornetto, T. and Estevez, I. 2001. Influence of vertical panels on use of space by domestic fowl. Applied Animal Behaviour Science 71(2), 141-153.

Cornetto, T., Estevez, I. and Douglass, L. W. 2002. Using artificial cover to reduce aggression and disturbances in domestic fowl. Applied Animal Behaviour Science 75(4), 325-336.

Dal Bosco, A., Mugnai, C., Sirri, F., Zamparini, C. and Castellini, C. 2010. Assessment of a global positioning system to evaluate activities of organic chickens at pasture. Journal of Applied Poultry Research 19(3), 213-218.

David, B., Mejdell, C., Michel, V., Lund, V. and Moe, R. O. 2015a. Air quality in alternative housing systems may have an impact on laying hen welfare. Part II: ammonia. Animals 5(3), 886-896.

David, B., Moe, R. O., Michel, V., Lund, V. and Mejdell, C. 2015b. Air quality in alternative housing systems may have an impact on laying hen welfare. Part l: Dust. Animals 5, 495-511.

Dawkins, M. S. and Layton, R. 2012. Breeding for better welfare: genetic goals for broiler chickens and their parents. Animal Welfare 21(2), 147-155.

de Gouw, P., van de Ven, L. J. F., Lourens, S., Kemp, B. and van den Brand, H. 2017. Effects of dust, formaldehyde and delayed feeding on early postnatal development of broiler chickens. Research in Veterinary Science 112, 201-207.

de Jong, I. C., Berg, C., Butterworth, A. and Estevez, I. 2012a. Scientific Report Updating the EFSA Opinions on the Welfare of Broilers and Broiler Breeders. Supporting Publications 2012:EN-295, [116pp]. Available at: www.efsa.europa.eu /publications.

de Jong, I. C. and Goertz, M. 2017. Broiler chicken stocking density affects use of environmental enrichment objects. Xth European Symposium on Poultry Welfare, Xth European Symposium on Poultry Welfare Ploufragan, France, p. 69.

de Jong, I. C. and Gunnink, H. 2019. Effects of a commercial broiler enrichment programme with or without natural light on behaviour and other welfare indicators. Animal 13(2), 384-391.

de Jong, I. C., Gunnink, H. and van Harn, J. 2014. Wet litter not only induces footpad dermatitis but also reduces overall welfare, technical performance, and carcass yield in broiler chickens. Journal of Applied Poultry Research 23(1), 51-58. 
de Jong, I. C., Gunnink, H., van Hattum, T., van Riel, J. W., Raaijmakers, M. P., Zoet, E. S. and Van den Brand, H. 2019. Comparison of performance, health and welfare aspects between commercially housed hatchery-hatched and on-farm hatched broiler flocks. Animal 13, 1269-1277.

de Jong, I. C., van Harn, J., Gunnink, H., Hindle, V. A. and Lourens, A. 2012b. Footpad dermatitis in Dutch broiler flocks: prevalence and factors of influence. Poultry Science 91(7), 1569-1574.

de Jong, I. C., van Riel, J., Bracke, M. B. M. and van den Brand, H. 2017. A 'meta-analysis' of effects of post-hatch food and water deprivation on development, performance and welfare of chickens. PLoS ONE 12(12), e0189350.

de Jong, I. C. and Van Wijhe-Kiezebrink, M. C. 2014. Use of different types of enrichment in slower growing broilers: a pilot study. Wageningen Livestock Research, Report 810, Wageningen, p. 39. Available at: https://edepot.wur.nl/318861.

de Jong, I. C., Veldkamp, T. and Van Harn, J. 2013. Management tools to reduce footpad dermatitis in broiler chickens, 19th European Symposium on Poultry Nutrition, German Branch of the WPSA, Potsdam, Germany, pp. 78-83.

de Jonge, J. and van Trijp, H. 2014. Heterogeneity in consumer perceptions of the animal friendliness of broiler production systems. Food Policy 49, 174-185.

Deep, A., Raginski, C., Schwean-Lardner, K., Fancher, B. I. and Classen, H. L. 2013. Minimum light intensity threshold to prevent negative effects on broiler production and welfare. British Poultry Science 54(6), 686-694.

Dixon, L. M. 2020. Slow and steady wins the race: the behaviour and welfare of commercial faster growing broiler breeds compared to a commercial slower growing breed. PLOS ONE 15(4), e0231006. doi:10.1371/journal. pone.0231006.

Duve, L. R., Steenfeldt, S., Thodberg, K. and Nielsen, B. L. 2011. Splitting the scotoperiod: effects on feeding behaviour, intestinal fill and digestive transit time in broiler chickens. British Poultry Science 52(1), 1-10.

EFSA 2010. Scientific Opinion on the influence of genetic parameters on the welfare and the resistance to stress of commercial broilers. EFSA Journal 8(7), 1666.

Ellen, H. H., Leenstra, F., Emous, R. A., Groenestein, K., Van Harn, J., Van Horne, P., de Jong, I. C., Kense, M., Mevius, D. and Wagenaar, J. A. 2012. Broiler Production Systems in the Netherlands, Wageningen Livestock Research, Wageningen, Report 819, 53 pp. Available at: http://library.wur.nl/WebQuery/wurpubs/fulltext/222179.

Estevez, I. and Newberry, R. C. 2017. The contribution of environmental enrichment to sustainable poultry production. In: Applegate, T. (Ed.), Achieving Sustainable Production of Poultry Meat. Burleigh Dodds Science Publishing Limited, Cambridge, UK, pp. 247-279.

European Commission 2007. The EU broiler directive 2010/43/EC. Available at: https:// eur-lex.europa.eu/eli/dir/2007/43/oj. Accessed on 13/10/19.

European Commission 2016. Use of Slaughterhouse Data to Monitor Welfare of Broilers on Farm. doi:10.2772/57892.

Federici, J. F., Vanderhasselt, R., Sans, E. C. O., Tuyttens, F. A. M., Souza, A. P. O. and Molento, C. F. M. 2016. Assessment of broiler chicken welfare in Southern Brazil. Revista Brasileira de Ciência Avícola 18(1), 133-140.

Gerritzen, M., Verkaik, J., Reimert, H., Gunnink, H., Van Hattum, T. and de Jong, I. C. 2019. Letsel en schade bij vleeskuikens als gevolg van vangen, transport en handelingen aan de slachtlijn. Wageningen Livestock Research, Wageningen, Report 1107, 53 pp. doi:10.18174/467902. 
Hall, A. L. 2001. The effect of stocking density on the welfare and behaviour of broiler chickens reared commercially. Animal Welfare 10, 23-40.

Haslam, S. M., Knowles, T. G., Brown, S. N., Wilkins, L. J., Kestin, S. C., Warriss, P. D. and Nicol, C. J. 2007. Factors affecting the prevalence of foot pad dermatitis, hock burn and breast burn in broiler chicken. British Poultry Science 48(3), 264-275.

Hedlund, L., Whittle, R. and Jensen, P. 2019. Effects of commercial hatchery processing on short- and long-term stress responses in laying hens. Scientific Reports 9, 2367. doi:10.1038/s41598-019-38817-y.

Hiemstra, S. and Ten Napel, J. 2011. Study of the Impact of Genetic Selection on the Welfare of Chickens Bred and Kept for Meat Production. DG SANCO Letter of Contract N ${ }^{\circ}$ SANCO/2011/12254 Final Report, 118 pp. https://ec.europa.eu/food /sites/food/files/animals/docs/aw:practice_farm_broilers_653020_final-report_en .pdf

Hollemans, M. S., de Vries, S., Lammers, A. and Clouard, C. 2018. Effects of early nutrition and transport of 1-day-old chickens on production performance and fear response. Poultry Science 97(7), 2534-2542.

Huth, J. C. and Archer, G. S. 2015. Comparison of two LED light bulbs to a dimmable CFL and their effects on broiler chicken growth, stress, and fear. Poultry Science 94(9), 2027-2036.

Jacobs, L., Delezie, E., Duchateau, L., Goethals, K., Ampe, B., Buyse, J. and Tuyttens, F. A. M. 2017. Impact of transportation duration on stress responses in day-old chicks from young and old breeders. Research in Veterinary Science 112, 172-176.

Jones, E. K. M., Wathes, C. M. and Webster, A. J. F. 2005. Avoidance of atmospheric ammonia by domestic fowl and the effect of early experience. Applied Animal Behaviour Science 90(3-4), 293-308.

Karaarslan, S. and Nazligul, A. 2018. Effects of lighting, stocking density, and access to perches on leg health variables as welfare indicators in broiler chickens. Livestock Science 218, 31-36.

Kaukonen, E., Norring, M. and Valros, A. 2017. Perches and elevated platforms in commercial broiler farms: use and effect on walking ability, incidence of tibial dyschondroplasia and bone mineral content. Animal 11(5), 864-871.

Kestin, S. C., Su, G. and Sorensen, P. 1999. Different commercial broiler crosses have different susceptibilities to leg weakness. Poultry Science 78(8), 1085-1090.

Kittelsen, K. E., David, B., Moe, R. O., Poulsen, H. D., Young, J. F. and Granquist, E. G. 2017. Associations among gait score, production data, abattoir registrations, and postmortem tibia measurements in broiler chickens. Poultry Science 96(5), 1033-1040.

Knierim, U. 2013. Effects of stocking density on the behaviour and bodily state of broilers fattened with a target live weight of $2 \mathrm{~kg}$. Berliner Und Munchener Tierarztliche Wochenschrift 126(3-4), 149-155.

Knowles, T. G., Kestin, S. C., Haslam, S. M., Brown, S. N., Green, L. E., Butterworth, A., Pope, S. J., Pfeiffer, D. and Nicol, C. J. 2008. Leg disorders in broiler chickens: prevalence, risk factors and prevention. PLOS ONE 3, e1545

Kyvsgaard, N. C., Jensen, H. B., Ambrosen, T. and Toft, N. 2013. Temporal changes and risk factors for foot-pad dermatitis in Danish broilers. Poultry Science 92(1), $26-32$.

Leone, E. H., Christman, M. C., Douglass, L. and Estevez, I. 2010. Separating the impact of group size, density, and enclosure size on broiler movement and space use at a decreasing perimeter to area ratio. Behavioural Processes 83(1), 16-22. 
Leone, E. H. and Estevez, I. 2008a. Space use according to the distribution of resources and level of competition. Poultry Science 87(1), 3-13.

Leone, E. H. and Estevez, I. 2008b. Use of space in the domestic fowl: separating the effects of enclosure size, group size and density. Animal Behaviour 76(5), 1673-1682.

Leone, E. H., Estevez, I. and Christman, M. C. 2007. Environmental complexity and group size: immediate effects on use of space by domestic fowl. Applied Animal Behaviour Science 102(1-2), 39-52.

Lindholm, C., Karlsson, L., Johansson, A. and Altimiras, J. 2016. Higher fear of predators does not decrease outdoor range use in free-range rowan ranger broiler chickens. Acta Agriculturae Scandinavica, Section A - Animal Science 66(4), 231-238.

Louton, H., Keppler, C., Erhard, M., van Tuijl, O., Bachmeier, J., Damme, K., Reese, S. and Rauch, E. 2019. Animal-based welfare indicators of 4 slow-growing broiler genotypes for the approval in an animal welfare label program. Poultry Science 98(6), 2326-2337.

Lund, V. P., Nielsen, L. R., Oliveira, A. R. S. and Christensen, J. P. 2017. Evaluation of the Danish footpad lesion surveillance in conventional and organic broilers: misclassification of scoring. Poultry Science 96(7), 2018-2028.

Malchow, J., Berk, J., Puppe, B. and Schrader, L. 2019a. Perches or grids? What do rearing chickens differing in growth performance prefer for roosting? Poultry Science 98(1), 29-38.

Malchow, J., Puppe, B., Berk, J. and Schrader, L. 2019b. Effects of elevated grids on growing male chickens differing in growth performance. Frontiers in Veterinary Science 6:203. doi:10.3389/fvets.2019.00203

Mallapur, A., Miller, C., Christman, M. C. and Estevez, I. 2009. Short-term and long-term movement patterns in confined environments by domestic fowl: influence of group size and enclosure size. Applied Animal Behaviour Science 117(1-2), 28-34.

Mendes, A. S., Paixao, S. J., Restelatto, R., Morello, G. M., de Moura, D. J. and Possenti, J. C. 2013. Performance and preference of broiler chickens exposed to different lighting sources. Journal of Applied Poultry Research 22(1), 62-70.

Mitchell, M. A. 2009. Chick transport and welfare. Avian Biology Research 2(1-2), 99-105.

Nielsen, B. L., Kjaer, J. B. and Friggens, N. C. 2004. Temporal changes in activity measured by passive infrared detection (PID) of broiler strains growing at different rates. Archiv fur Geflugelkunde 68, 106-110.

Nielsen, B. L., Thomsen, M. G., Soerensen, J. P. and Young, J. F. 2003. Feed and strain effects on the use of outdoor areas by broilers. British Poultry Science 44(2), 161-196.

Opengart, K., Bilgili, S. F., Warren, G. L., Baker, K. T., Moore, J. D. and Dougherty, S. 2018. Incidence, severity, and relationship of broiler footpad lesions and gait scores of market-age broilers raised under commercial conditions in the southeastern United States. Journal of Applied Poultry Research 27(3), 424-432.

Pedersen, I. J. and Forkman, B. 2019. Improving leg health in broiler chickens: a systematic review of the effect of environmental enrichment. Animal Welfare 28(2), 215-230.

Pettit-Riley, R., Estevez, I. and Russek-Cohen, E. 2002. Effects of crowding and access to perches on aggressive behaviour in broilers. Applied Animal Behaviour Science 79(1), 11-25.

Prescott, N. B. and Wathes, C. M. 1999. Spectral sensitivity of the domestic fowl (Gallus $\mathrm{g}$. domesticus). British Poultry Science 40(3), 332-339.

Rauch, E., Keppler, C., Damme, K., Hausleitner, M., Bachmeier, J., Hartmann, J. and Louton, H. 2017. Test of different premium broiler genotypes under Animal Welfare 
Label conditions. Part II: animal health. European Poultry Science 81. doi:10.1399/ eps.2017.169.

Rault, J. L., Clark, K., Groves, P. J. and Cronin, G. M. 2017. Light intensity of 5 or 20 lux on broiler behavior, welfare and productivity. Poultry Science 96(4), 779-787.

Rayner, A., Newberry, R. C., Vas, J., Butterworth, A. and Mullan, S. 2019. Growing Slowly with More Space: Effects on "Positive Behaviours" in Broiler Chickens. ISAE, Bergen.

Riber, A. B. 2015. Effects of color of light on preferences, performance, and welfare in broilers. Poultry Science 94(8), 1767-1775.

Riber, A. B., van de Weerd, H. A., de Jong, I. C. and Steenfeldt, S. 2018. Review of environmental enrichment for broiler chickens. Poultry Science 97(2), 378-396.

Rodenburg, T. B., Coenen, E. and Van Harn, J. 2004. Goed gebruik overdekte uitloop. Pluimveehouderij 34, 10-11.

Rodriguez-Aurrekoetxea, A., Leone, E. H. and Estevez, I. 2015. Effects of panels and perches on the behaviour of commercial slow-growing free-range meat chickens. Applied Animal Behaviour Science 165, 103-111.

RSPCA 2006. Everyone's a Winner. How Rearing Chickens to Higher Welfare Standards Can Benefit the Chicken, Producer, Retailer and Consumer. RSPCA, Horsam, WestSussex, UK, pp. 26.

Saatkamp, H. W., Vissers, L. S. M., Van Horne, P. L. M. and de Jong, I. C. 2019. Transition from conventional broiler meat to meat from production concepts with higher animal welfare: experiences from the Netherlands. Animals 9(8), 483.

Sanotra, G. S., Lund, J. D., Ersboll, A. K., Petersen, J. S. and Vestergaard, K. S. 2001. Monitoring leg problems in broilers: a survey of commercial broiler production in Denmark. World's Poultry Science Journal 57(1), 55-69.

Schwean-Lardner, K., Fancher, B. I. and Classen, H. L. 2012. Impact of daylength on behavioural output in commercial broilers. Applied Animal Behaviour Science 137(1-2), 43-52.

Shepherd, E. M., Fairchild, B. D. and Ritz, C. W. 2017. Alternative bedding materials and litter depth impact litter moisture and footpad dermatitis. Journal of Applied Poultry Research 26(4), 518-528.

Shields, S. and Greger, M. 2003. Animal welfare and food safety aspects of confining broiler chickens to cages. Animals 3(2), 386-400.

Shields, S. J., Garner, J. P. and Mench, J. A. 2004. Dustbathing by broiler chickens: a comparison of preference for four different substrates. Applied Animal Behaviour Science 87(1-2), 69-82.

Shields, S. J., Garner, J. P. and Mench, J. A. 2005. Effect of sand and wood-shavings bedding on the behavior of broiler chickens. Poultry Science 84(12), 1816 $-1824$.

Sossidou, E. N., Dal Bosco, A., Castellini, C. and Grashorn, M. A. 2015. Effects of pasture management on poultry welfare and meat quality in organic poultry production systems. World's Poultry Science Journal 71(2), 375-384.

Souillard, R., Reperant, J. M., Experton, C., Huneau-Salaun, A., Coton, J., Balaine, L. and Le Bouquin, S. 2019. Husbandry practices, health, and welfare status of organic broilers in France. Animals 9, 97. doi:10.3390/ani9030097.

Stadig, L. M., Rodenburg, T. B., Ampe, B., Reubens, B. and Tuyttens, F. A. M. 2017. Effects of shelter type, early environmental enrichment and weather conditions on free-range behaviour of slow-growing broiler chickens. Animal 11(6), 1046 -1053 . 
Stadig, L. M., Rodenburg, T. B., Reubens, B., Ampe, B. and Tuyttens, F. A. M. 2018. Effects of dark brooders and overhangs on free-range use and behaviour of slow-growing broilers. Animal 12(8), 1621-1630.

Statistica 2019. Production of meat worldwide from 2016 to 2019, by type. Available at: https://www.statista.com/statistics/237632/production-of-meat-worldwide-since -1990/. Accessed on 05/08/2019.

Steenfeldt, S., Sorensen, P. and Nielsen, B. L. 2019. Effects of choice feeding and lower ambient temperature on feed intake, growth, foot health, and panting of fast- and slow-growing broiler strains. Poultry Science 98(2), 503-513.

Sun, Y. Y., Li, Y. L., Li, D. L., Chen, C., Bai, H., Xue, F. G. and Chen, J. L. 2017. Responses of broilers to the near-continuous lighting, constant 16-h lighting, and constant 16-h lighting with a 2-h night interruption. Livestock Science 206, 135-140.

Swiatkiewicz, S., Arczewska-Wlosek, A. and Jozefiak, D. 2017. The nutrition of poultry as a factor affecting litter quality and foot pad dermatitis - an updated review. Journal of Animal Physiology and Animal Nutrition 101(5), e14-e20.

Tahamtani, F. M., Pedersen, I. J., Toinon, C. and Riber, A. B. 2018. Effects of environmental complexity on fearfulness and learning ability in fast growing broiler chickens. Applied Animal Behaviour Science 207, 49-56.

Taylor, P. S., Hemsworth, P. H., Groves, P. J., Gebhardt-Henrich, S. G. and Rault, J. L. 2017a. Ranging behaviour of commercial free-range broiler chickens 1: factors related to flock variability. Animals 7, 54. doi:10.3390/ani7070054.

Taylor, P. S., Hemsworth, P. H., Groves, P. J., Gebhardt-Henrich, S. G. and Rault, J. L. 2017b. Ranging behaviour of commercial free-range broiler chickens 2: individual variation. Animals 7, 55. doi:10.3390/ani7070055.

Torrey, S., Liu, Z., Caston, L., Nascimento dos Santos, M., Rothschild, D., Kiarie, E., Mandell, I. and Widowski, T. 2019. Differences in behavioural time budget between conventional and slow growing broiler chickens. Poultry Science Association Meeting, Poultry Science Association, Montreal.

Van Middelkoop, K., Van Harn, J., Wiers, W. and Van Horne, P. 2002. Slower growing broilers pose lower welfare risks. World Poultry 18, 20-21.

Van Niekerk, T., Ellen, H. H. and Winkel, A. 2016. Licht op licht: licht en verlichting in de pluimveehouderij in relatie tot beschadigend pikgedrag. Wageningen Livestock Research, Wageningen, Report 922, 33 pp.

Vasdal, G., Vas, J., Newberry, R. C. and Moe, R. O. 2019. Effects of environmental enrichment on activity and lameness in commercial broiler production. Journal of Applied Animal Welfare Science 22(2), 197-205.

Ventura, B. A., Siewerdt, F. and Estevez, I. 2012. Access to barrier perches improves behavior repertoire in broilers. PLoS ONE 7(1), e29826.

Vissers, L. S. M., de Jong, I. C., van Horne, P. L. M. and Saatkamp, H. W. 2019. Global prospects of the cost-efficiency of broiler welfare in middle-segment production systems. Animals 9, 473. doi:10.3390/ani9070473.

Wallenbeck, A., Wilhelmsson, S., Jonsson, L., Gunnarsson, S. and Yngvesson, J. 2016. Behaviour in one fast-growing and one slower-growing broiler (Gallus gallus domesticus) hybrid fed a high-or low-protein diet during a 10-week rearing period. Acta Agriculturae Scandinavica, Section A - Animal Science 66(3), 168-176.

Welfare Quality 2009, The Welfare Quality Assessment Protocol for Broiler Chickens and Laying Hens. The Welfare Quality Consortium, Lelystad. 
Wilhelmsson, S., Yngvesson, J., Jonsson, L., Gunnarsson, S. and Wallenbeck, A. 2019. Welfare Quality (R) assessment of a fast-growing and a slower-growing broiler hybrid, reared until 10 weeks and fed a low-protein, high-protein or mussel-meal diet. Livestock Science 219, 71-79.

Willemsen, H., Debonne, M., Swennen, Q., Everaert, N., Careghi, C., Han, H., Bruggeman, V., Tona, K. and Decuypere, E. 2010. Delay in feed access and spread of hatch: importance of early nutrition. World's Poultry Science Journal 66(2), 177-188.

Zuidhof, M. J., Schneider, B. L., Carney, V. L., Korver, D. R. and Robinson, F. E. 2014. Growth, efficiency, and yield of commercial broilers from 1957, 1978, and 2005. Poultry Science 93(12), 2970-2982. 
